\title{
Re-NetTA. Re-Manufacturing Networks for Tertiary Architectures
}

\author{
Cinzia Talamo, Monica Lavagna, Carol Monticelli, Nazly Atta, \\ Serena Giorgi and Salvatore Viscuso
}

\begin{abstract}
The paper introduces the on-going project Re-NetTA, which contributes to apply circular economy in the building sector, focusing on tertiary sector building components, characterized by rapid obsolescence and temporary uses. The ReNetTA project identifies re-manufacturing and reuse networks and processes as tools to reduce the generation of waste deriving from renewals/transformations carried out on short-term cycles, applying Life Cycle Management and sustainable business models. The goal is to maintain over time the value of the environmental and economic resources, integrated into manufactured products, once they have been removed from buildings, extending their useful life and their usability with the least possible consumption of other materials and energy and with the maximum containment of emissions into the environment. At first, the paper shows how circular economy can be applied to the built environment, according to literature. Secondly, the problem of waste coming from renewal interventions, carried out on short-term cycles of the tertiary sector, is discussed on quantitative data. Consequently, the aims of the research and the methodology, based on an interdisciplinary approach, are introduced. Finally, the research output is pointed out, highlighting the related economic, environmental, and social impacts.
\end{abstract}

Keywords Circular economy $\cdot$ Re-manufacturing $\cdot$ Built environment • Stakeholder networking $\cdot$ Circular business models $\cdot$ Life cycle approach

\section{Introduction}

European Commission (2015) identifies the construction sector as a fundamental driver-sector for the activation of circular economy. According to the statistical data in EU-28, the main field that produces waste is construction sector, contributing to $33.5 \%$ of the total waste generated by all economic activities and households

C. Talamo $(\varangle) \cdot$ M. Lavagna $\cdot$ C. Monticelli $\cdot$ N. Atta $\cdot$ S. Giorgi $\cdot$ S. Viscuso Architecture, Built Environment and Construction Engineering-ABC Department, Politecnico di Milano, Milan, Italy

e-mail: cinzia.talamo@polimi.it 
in 2014 in the EU-28 (Eurostat 2016). Moreover, the construction sector gives a lot of opportunities in job creation (currently, it provides 18 million direct jobs), contributing to about the $9 \%$ of the EU's GDP (European Commission 2018).

From 2015, the efforts to apply circular economy in the construction sector are increasing. However, currently, the circular strategy, more promoted and applied, regards waste management toward recycling (Giorgi et al. 2017). A lot of European Projects (e.g., HISER PROJECT, Resource Efficient Use of Mixed Waste, DEMOCLES, ENCORT) and particularly Life Project (e.g., LIFE-PSLOOP Polystyrene Loop; CDW recycling Innovative solution for the separation of construction and demolition waste) investigate specific recycling strategies (inter-sectoral or within the construction sector) of construction and demolition waste (Talamo and Migliore 2017). Moreover, the largest number of recycling case studies in the construction sector regards downcycling process (such as recycling of inert as road substrate). Instead, from a sustainable circular economy point of view, it is important to consider more valuable strategies that aim to avoid the generation of waste in upstream, encouraging reuse practices and the life cycle extension of products.

Ellen MacArthur Foundation and CE100 network (2016) suggest the six actions, within the "ReSOLVE framework" (regenerate, share, optimize, loop, virtualise, exchange), to guide the transition toward a circular economy in the built environment highlighting the objective of keeping resources into the cycles, creating new uses for materials. This approach can open up new scenarios of a building materials market and it has the potential for developing business model innovations. Other research works (Cheshire 2016; Durmisevic 2018) consider the "Design for Disassembly" as a valuable design strategy in order to encourage reuse processes at the end of the product service life.

Starting from this background, the research Re-NetTA, funded by Fondazione CARIPLO for the period 2019-2021, aims to define new organizational and operational models and new business strategies necessary to launch circular and regenerative economy processes based on re-manufacturing and involving the construction and the manufacturing sectors. The research focuses on buildings for the tertiary sector, usually characterized by quick cycles of renewal and reconfiguration, with the aim of creating the organizational and business conditions to make buildings "components banks" in a circular economy perspective.

\section{From Waste to Resources: Short-Term Components from Tertiary Sector and Temporary Use}

Some parts of the building have a long service life, while other parts and components have a short service life, requiring frequent replacement cycles and thus becoming potential waste, even though they still have good residual performances. BAMB report (Peters et al. 2017) indicates how often the different categories of products 

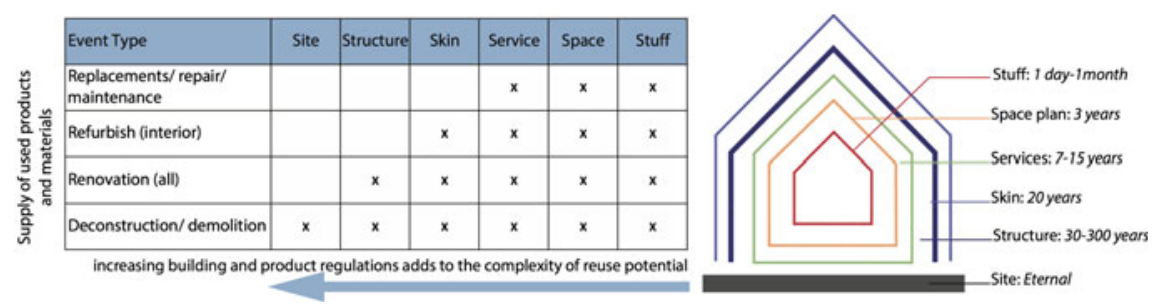

Fig. 1 Frequency of availability of building/product supply by event. Source BAMB 2017 (on the left), and Stewart Brand's 6 S's from "How Buildings Learn" (on the right)

need a replacement, in relation to the different interventions types (Fig. 1). The categories of products are based on the six S's system of building from Brand (1994) theory, which identifies the lifespan of each category. This analysis shows that Stuff (furniture, appliances, objects), Space plan (division of space, interior partition) and Services (HVAC systems and moving parts like elevators) not only have a short lifespan, but also, for each type of intervention (demolition, total renovation, interior renovation, and small upgrades and maintenance), they are always substituted. Starting from these issues, the research Re-NetTA investigates the potential second life or the extension of the life of products, characterized by short-term service life. The research focuses on short-term components with a service life lower than 15 years (interiors, services, equipment, furnishings, and fittings), which frequently became potential waste that can be converted into new resources.

These interventions are more frequent in tertiary buildings, especially during the activity of buying and selling. In fact, there is a direct relationship between the number of trades and the number of internal components/fittings renewals due to the accelerated obsolescence, caused by the change of the owners and, therefore, by a change of their needs and requests.

The data from the Rapporto Immobiliare (2017) shows that the share percentage of stocks bought and sold, in a given period, of buildings destined for offices and shops reaches a maximum peak in Lombardy. According to this report, the Real Estate units of the office type, in 2016, are 643,629 in Italy. Among the regions, Lombardy emerges with 140,229 units (which represent $21.8 \%$ of the national stock). Regarding the sales volumes of offices, Lombardy alone accounts for more than a quarter of the national exchanges (28.4\% of the total number of transition). For the Real Estate units of the shop type also, Lombardy has the greatest presence of shops: 367,862 units of 2,549,924 Italian units, covering a share of stores of $14.4 \%$. As regards the sales and purchases of shops, Lombardy_which alone represents almost 1/5 of the national market-shows a $+13.9 \%$ rise in the market in 2016 compared to 2015 . Moreover, the report of Cresme (2016) shows how in the city of Milan the amount of buildings available for lease is preponderant (74.6\% of the total management properties offered) and increasing (+10.6\% in the period 2014-2015).

Accelerated obsolescence of internal components/fittings is also typical in the exhibition and fair field. These activities entail a huge amount of internal fittings 
and dry disassembled solutions, characterized by high obsolescence, requiring frequent interventions of disassembling/renewal/transformation. The report of Regione Lombardia (2016) shows that Lombardy is the first Italian region for exhibition activities, with over $600,000 \mathrm{~m}^{2}$ of gross covered surfaces. The regional offer of exhibition spaces is concentrated in Milan (62\% of the overall availability of covered spaces).

The presence in Lombardy of a substantial vast tertiary building stock, characterized by subject to frequent renewals/transformations, due to accelerated obsolescence, generates increasing quantities of materials and components-often dry-assembled-still embodying high added value.

Starting from these data, the research considers the specific field of the tertiary sector and "temporary use," that generates a great amount of waste, in the Lombardy Region.

\section{Actions to Close the Cycle: Re-Manufacturing and ReUse Business Models}

For closing the loop of materials/components, strategies of reuse, repurpose, reconditioning, re-manufacturing, and recycling are encouraged (Fig. 2). According to the standard BS 8887:2:2009 (2009), the reuse is the operation through which a product is put back into use for the same purpose at its end of life, while the repurpose considers a new utilization of a product in a new role that differs from the original purpose

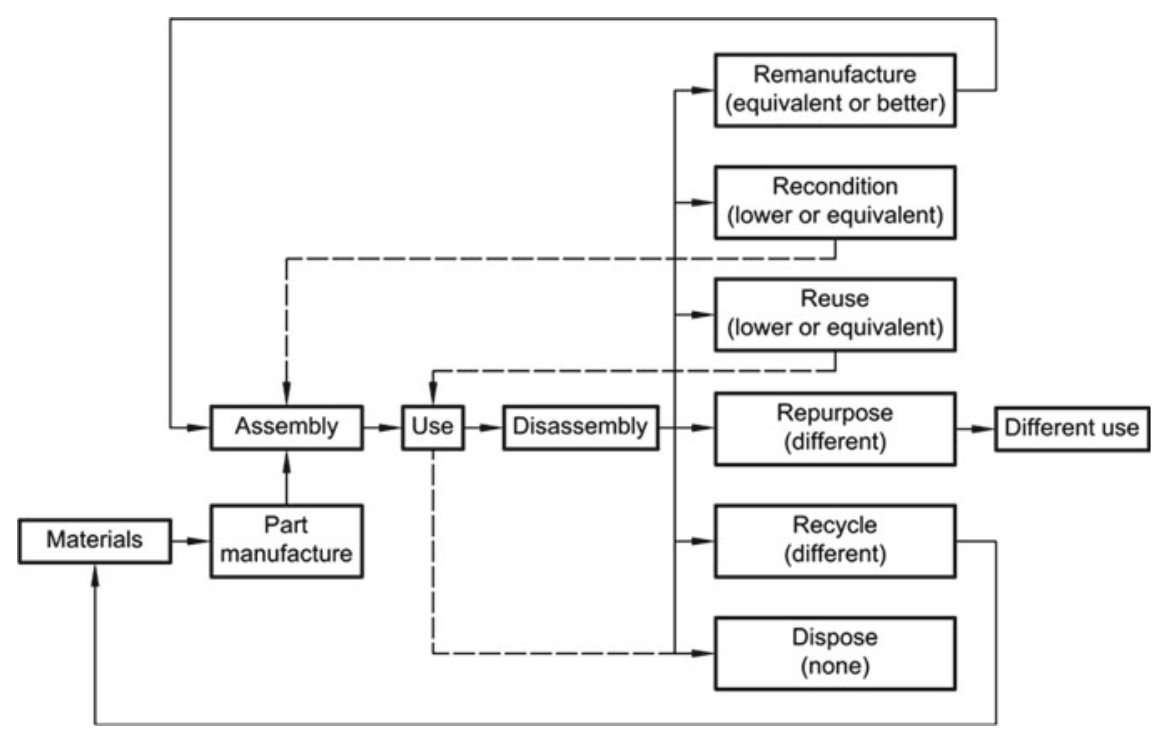

Fig. 2 Product lifecycle. Source BSBS 8887-2:2009. The likely change in warranty level compared to original product is given in parentheses 
it was designed to perform. Reconditioning regards the return of a used product to a satisfactory working condition, by rebuilding or repairing its major components (with a possible inferior performance, so the warranty is generally less than the new ones). Instead, re-manufacturing is the operation through which a used product returns at least to its original performance with a warranty that is equivalent to or better than that of the newly manufactured product. Recycling regards the process by which the waste is transformed into a secondary material for performing the original purpose or other purposes. Hence, in terms of value, according to the standard BS 8887:2:2009, re-manufacturing is the only process that returns a product characterized by the same, or higher, value than the original product.

Currently, in the built environment, only the movable parts of buildings such as furniture, chairs, desks, shelves are sometimes re-manufactured. Pursuing the circular economy objectives, the Center for Remanufacturing and Reusefounded the European Remanufacturing Network (2016) for academic research in order to encourage industrial re-manufacturing processes (Fig. 3) and business models in different sectors (aerospace, automotive, electronics, machinery, marine, rail).

The development of effective business models may boost re-manufacturing and reuse processes in the tertiary building sector (Osterwalder and Pigneur 2010). In a circular business model, the value creation depends on meeting a new demand for products, after their use, and on the utilization of the economic value retained within them (Linder and Williander 2017).

The deployment of the paradigm of the circular business model in the construction sector requires a profound change in actors' behaviors, in order to pursue the "downside" of ownership. New collaborative business models may allow the "access to" instead of the "ownership of" products, increasing the capacity utilization and thus the efficiency of the deployed resources. Relevant examples from this point of view are provided by other sectors that are now applying the principles of the socalled sharing economy (e.g., Arena et al. 2017) sustainable product-service systems (S.PSS).

A S.PSS is "an offer/business model providing an integrated mix of products and services that are together able to fulfil a particular customer demand ("unit of satisfaction"), based on innovative interactions between the stakeholders of the value production system (satisfaction system), where the ownership of the product/s and/or its life cycle responsibilities remain in the hands of the provider/s" (Vezzoli et al.

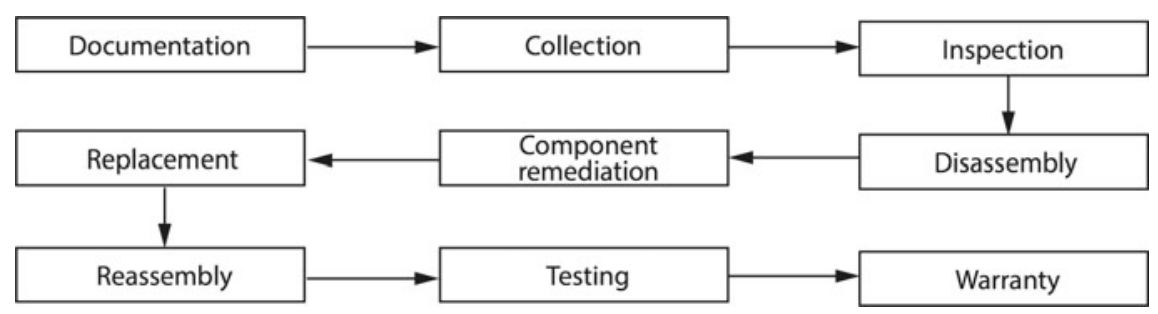

Fig. 3 A generic re-manufacturing process. Source ERN (2016) 
2014). The S.PSS models are based on radical innovations, not so much on technological ones, but more on new interactions/partnerships between the stakeholders of a particular satisfaction production chain (life cycle/s).

This new vision is closely related to the Life Cycle Management (LCM): a comprehensive analysis along with a change of the processes related to the product life cycle is necessary for sustainable development. Life Cycle Assessment (LCA) and Life Cycle Cost (LCC) are the supporting tools for decision-making, assessing the environmental and economic impacts of strategies (Lavagna 2008; Monticelli 2013).

The research (Fig. 4) transfers successful business models and S.PSS models applied in other sectors to the construction sector, in order to improve the competitiveness of various categories of stakeholders in Lombardy (e.g., small-medium manufacturing companies, FM services providers, etc.) by creating network relationships among operators. Moreover, the research applies the Life Cycle Thinking, using LCA and LCC as supporting tools during the Life Cycle Design (LCD) of new models, rules, and procedures to support innovative Life Cycle Management (LCM).

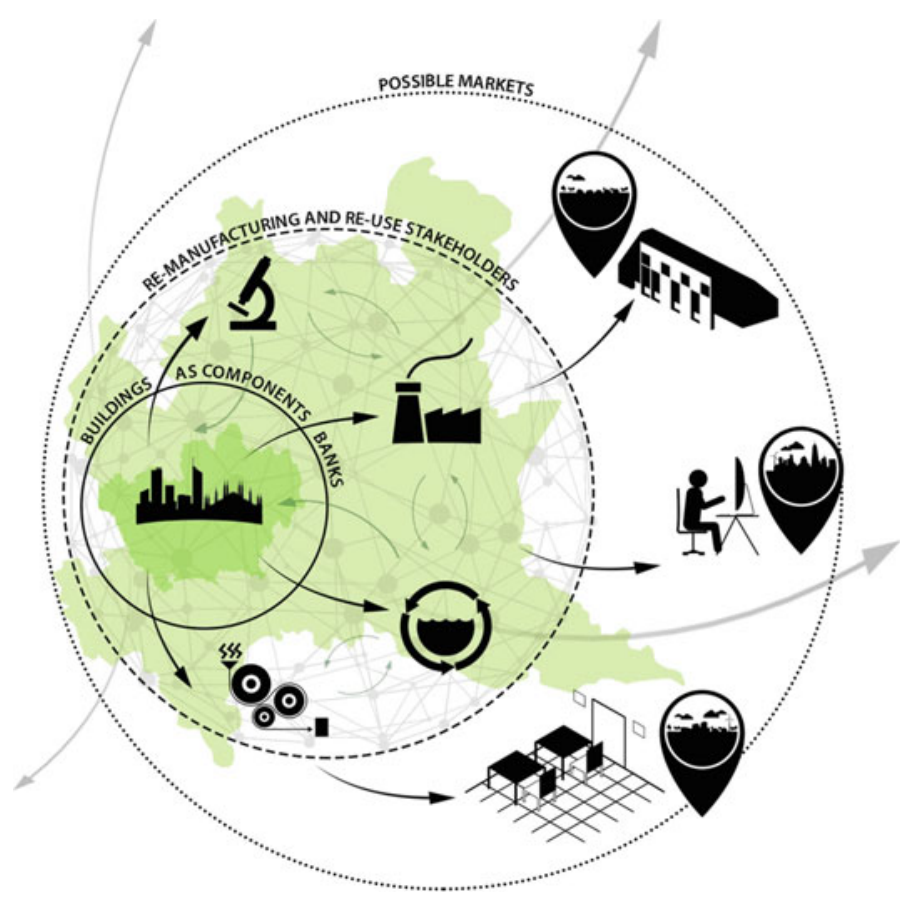

Fig. 4 Multi-scalar vision of the project. Source Re-NetTA Project 


\section{Methodology}

In order to define process innovations (in terms of new relationships between stakeholders, new supply chain networks, new methods of construction-use-disassembly and new organizational, operative and business models) related to re-manufacturing and reuse in the context of the transformation/renewal of buildings for the tertiary sector (offices, accommodation facilities, exhibition facilities, retail, temporary shops), the project follows a structured methodological approach characterized by crosssectoral collaboration and cross-fertilization, starting from the skills and knowledge that characterize three Disciplinary Scientific Sectors DSS) (Technology of Architecture and Building construction; Management and Industrial Engineering; Industrial Design and Communication) and the European Research Council (ERC) sector Sustainable Design and Eco-design.

The research is developed according to five phases, namely (Table 1):

- Phase 1. Best practices of Re-* (use, manufacturing) and transferable key criteria to the construction sector

- Phase 2. Field test and stakeholders' identification

- Phase 3. Framework of models, rules, and procedures for re-manufacturing of building components

- Phase 4. Pilot Network for Re-manufacturing and validation

- Phase 5. Management and dissemination

In particular, Table 1 shows the articulation of the research in these phases, highlighting their tasks and actions.

In each stage of the research, both DSS and ERC disciplines collaborate, firstly, adopting methods appropriate to each discipline and, secondarily, fertilizing them in a continuous discussion between the different disciplinary approaches. The outputs of each phase are shared among the different disciplinary approaches through the continuous cross-fertilization during the whole research duration. The research also involves crucial stakeholders (Real estate owners, designers, building components manufactures, construction firms, facility managers, SMEs associations, demolition companies, users, etc.) in order to deepen specific issues and validate the outputs of the project.

\section{Framework of Models, Rules and Procedures for Re-Manufacturing and Reuse of Building Components}

The final outcome of the research is a framework of models, rules, and procedures for re-manufacturing and reuse of building components, articulated in:

- Definition of the most suitable applications of "re-hierarchy" (re-manufacturing, recondition, repurpose, reuse, and repair) categories to the construction sector; 


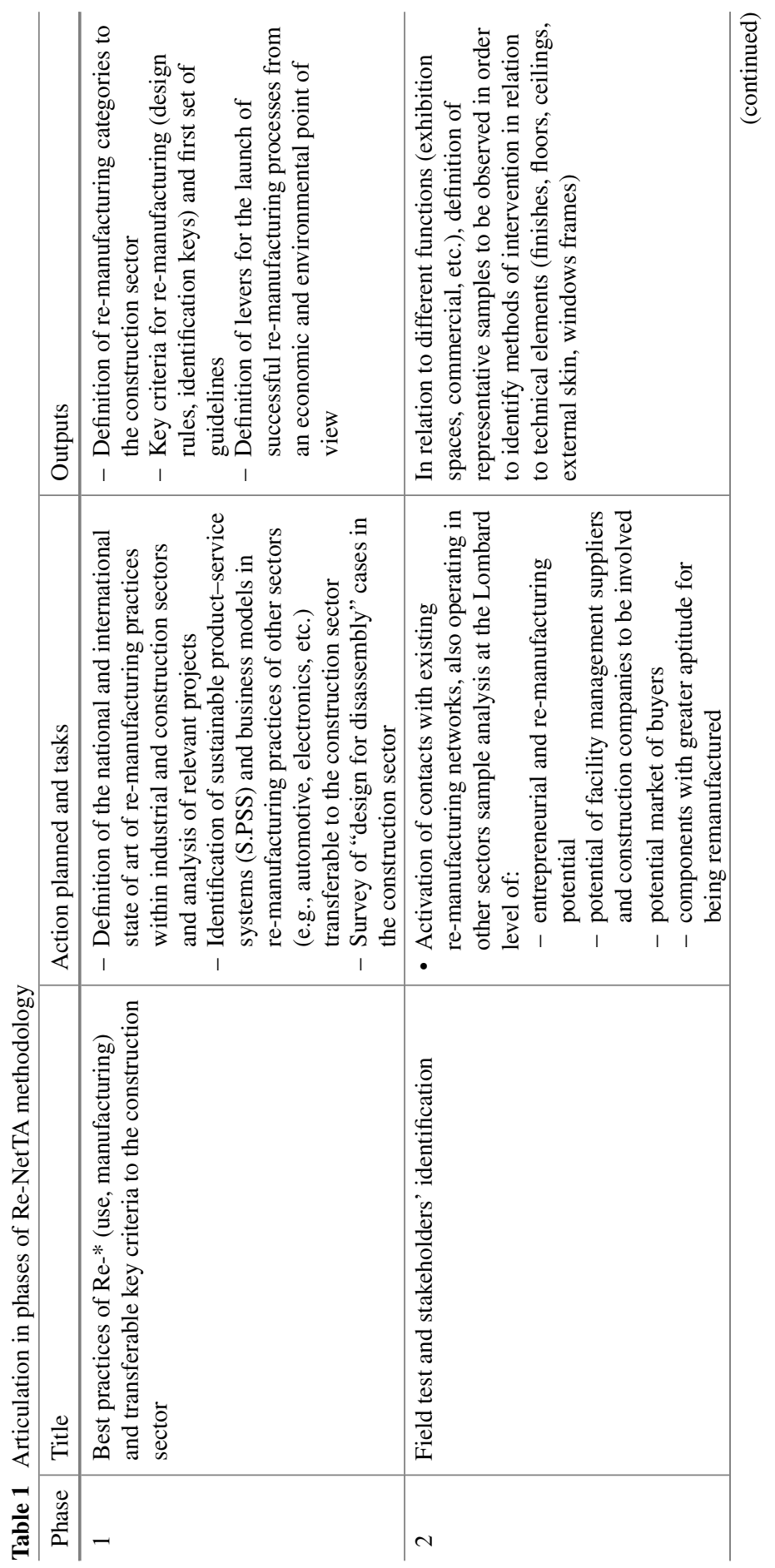




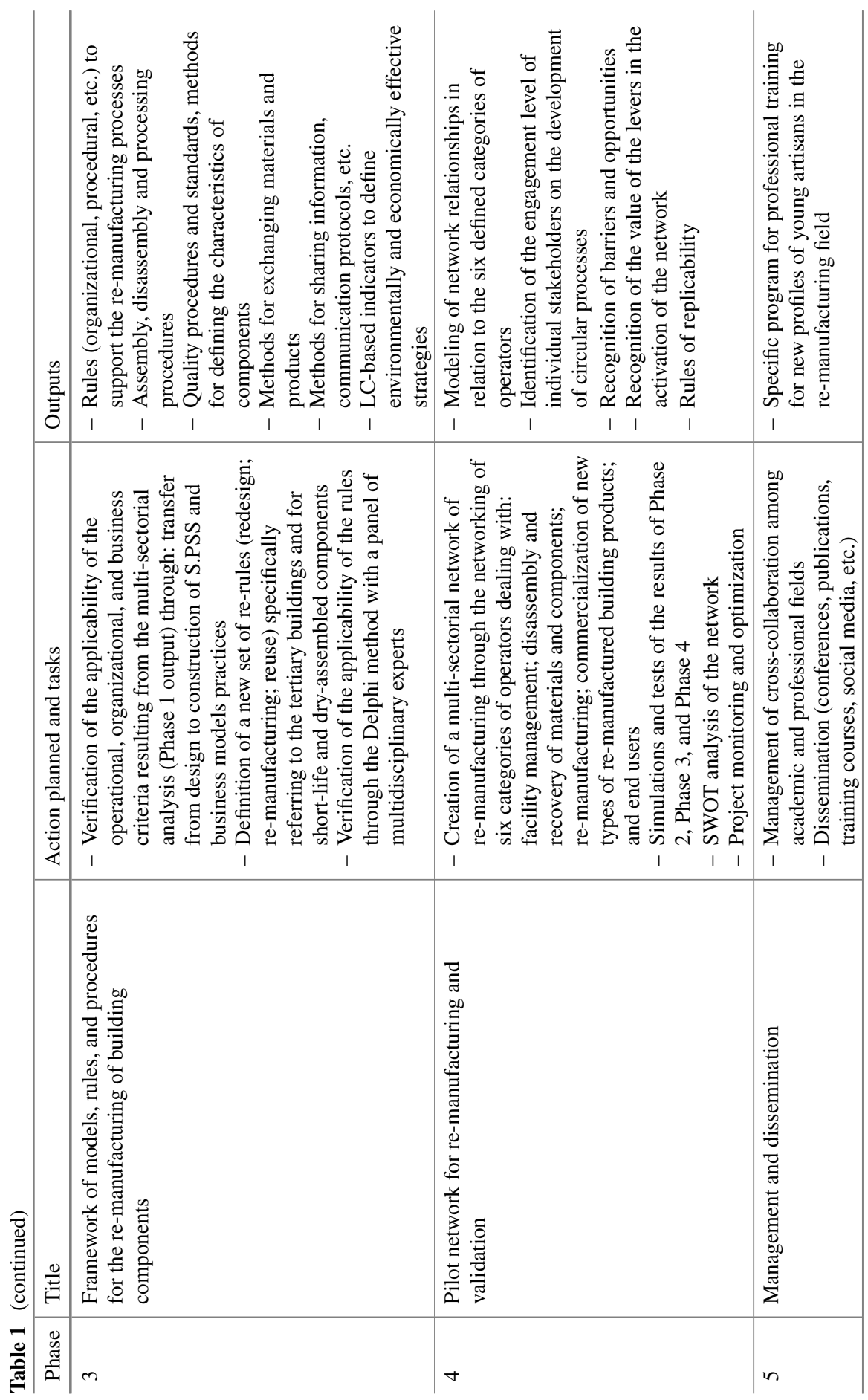


- Definition of key criteria for re-manufacturing: criteria for the design of components "to be re-manufactured"; interpretative keys to understand the remanufacturing attitude of a component to be disassembled and re-manufactured; obstacles/barriers (e.g., legislative) and levers (e.g., guarantee conditions, certified environmental value, economic value);

- Definition, through a multi-sectorial analysis, of: organizational conditions; criteria for the start of re-manufacturing processes; levers for the launch of successful re-manufacturing processes from an economic and environmental point of view; economic, environmental, and social benefits to be used as levers for the start-up of re-manufacturing processes.

- Definition of rules to support the re-manufacturing processes: relationship rules (organizational, procedural, etc.); assembly, disassembly, and processing procedures in relation to various technical elements (interior walls, finishes, floors, ceilings, external skin, windows frames); quality procedures, standards, and methods for defining the characteristics of components easy to be re-manufactured; methods for exchanging materials and products; methods for sharing information and communication protocols; procedures of application of LC-based indicators aiming at identifying the environmentally and economically more effective strategies to be adopted in re-manufacturing processes (e.g. definition of the maximum advantageous physical distance between disassembly site and remanufacturer).

For what concerns the impacts of the project-able to meet the strategies characterizing the circular economy approach-it is possible to mention:

\section{- Economic impacts}

- Extending the economic value of building components over time

- Increasing the opportunity to access to incentive or participate in public tendering in the construction sector

- Improving competitiveness through environmental certification schemes (Green Building Rating Systems)

\section{- Environmental impacts}

- Product life optimization (use extension and intensification)

- Reduction of environmental flows and impacts related to the extension of the service life of building components

- Reduction of downcycling and promotion of revalorisation

- Minimization of the materials toxicity through dry assembly

- Environmental value of embodied impacts (embodied energy, embodied carbon, and others)

- Social impacts

- Identification of possible new markets of "regenerated products" (e.g., social housing) 
- Identification of new job opportunities for young people with high-level skills (in the fields of: technical design, eco-design, management, and communication) or with low grade of studies (e.g., artisans)

\section{- Impacts on policies}

- Identification of possible framework barriers, obstacles, and conditions (regulation and standards) to overcome and adoption of effective action plans to reduce barriers

- Identification of incentives and promotion of policies

- Improvement of circular criteria in Green Building Rating Systems and in environmental certification, toward "circular products/service."

Lastly, the project stimulates the development of the local economic system by creating new cross-sectoral processes and relationships, as well as possibilities for new skills and jobs, and by improving the innovation capacity, competitiveness, and growth of SMEs in meeting the challenges of new potential markets.

\section{References}

Arena, M., Azzone, G., \& Bengo, I. (2017). Traditional and innovative vehicle-sharing models. In S. Savaresi \& A. Colorni (Eds.), Electric vehicle sharing services for smarter cities. Springer, Research for Development.

Brand, S. (1994). How buildings learn: What happens after they're built. USA: Penguin.

Cheshire, D. (2016). Building revolutions. Applying the circular economy to the built environment. New Castel: RIBA Publishing.

Cresme Ricerche S.p.A. (2016). Osservatorio sull'offerta di Immobili ad uso ufficio a Milano.

Durmisevic, E. (2018). WP3 reversible building design. Reversible building design guidelines. BAMB Report. Available at https://www.bamb2020.eu/wp-content/uploads/2018/12/ReversibleBuilding-Design-guidelines-and-protocol.pdf.

Ellen MacArthur Foundation and CE100. (2016). Circularity in the built environment: Case studies. Available at https://www.ellenmacarthurfoundation.org/assets/downloads/Built-Env-Co.Project. pdf.

ERN. (2016). Map of remanufacturing product design landscape.

European Commission. (2015). Closing the loop-An EU action plan for the Circular Economy, COM 614.

European Commission. (2018). Growth, construction. Available at https://ec.europa.eu/growth/ sectors/construction.

Eurostat. (2016). Key figures on Europe (pp. 161-164). Belgium.

Giorgi, S., Lavagna, M., \& Campioli, A. (2017). Economia Circolare, Gestione dei rifiuti e Life Cycle Thinking. Fondamenti, interpretazioni e analisi dello stato dell'arte. Ingegneria dell'Ambiente, $4(3), 245-254$.

Lavagna, M. (2008). Life cycle assessment in edilizia. Milano: Hoepli.

Linder, M., \& Williander, M. (2017). Circular business model innovation: Inherent uncertainties. Business Strategy and the Environment, 26, 182-196.

Monticelli, C. (2013).Life cycle design in architettura. Progetto e Valutazione di Impatto Ambientale dalla Materia all'Edificio. Maggioli, Santarcangelo di Romagna.

Osservatorio del Mercato Immobiliare. (2017). Rapporto Immobiliare 2017. Immobili a destinazione terziaria, commerciale e produttiva. Pubblicazioni OMI. 
Osterwalder, A., \& Pigneur, Y. (2010). Business model generation. Lausanne: Osterwalder \& Pigneur.

Peters, M., Ribeiro, A., Oseyran, J., \& Wang, K. (2017). Buildings as material banks and the need for innovative Business Models, BAMB report. Available at https://www.bamb2020.eu/wp-content/ uploads/2017/11/BAMB_Business-Models_20171114_extract.pdf.

Regione Lombardia. (2016). Sintesi del Rapporto "L'Attività Fieristica in Lombardia"n.14/2001-2016. Available at http://www.regione.lombardia.it/wps/wcm/connect/dbd5fb88a06c-4481-9a7d-2fde64c61914/Sintesi_Lombardia_2016.pdf?MOD=AJPERES\&CACHEID= dbd5fb88-a06c-4481-9a7d-2fde64c61914.

Talamo, C., \& Migliore, M. (2017). Le utilità dell'inutile. Economia circolare e strategie di riciclo dei rifiuti pre-consumo nel settore edilizio. Maggioli.

Vezzoli, C., Kohtala, C., \& Srinivasan, A. (2014). Product-service system design for sustainability. Sheffield: Greenleaf Publishing.

\section{Standards and Laws}

British Standard 8887-2:2009. (2009). Design for manufacture, assembly, disassembly and end-oflife processing (MADE). Terms and definitions.

Open Access This chapter is licensed under the terms of the Creative Commons Attribution 4.0 International License (http://creativecommons.org/licenses/by/4.0/), which permits use, sharing, adaptation, distribution and reproduction in any medium or format, as long as you give appropriate credit to the original author(s) and the source, provide a link to the Creative Commons license and indicate if changes were made.

The images or other third party material in this chapter are included in the chapter's Creative Commons license, unless indicated otherwise in a credit line to the material. If material is not included in the chapter's Creative Commons license and your intended use is not permitted by statutory regulation or exceeds the permitted use, you will need to obtain permission directly from the copyright holder. 